\title{
Research on Environmental Pollution regulation in China's Construction Industry
}

\author{
Shengpeng Yan* \\ Zhejiang University of Technology, Hangzhou310000, Zhejiang Province, China
}

*Corresponding author: Shengpeng Yan, 2111914020@zjut.edu.com

\begin{abstract}
China has proposed the notion of sustainable development in the framework of a hazardous society in response to global environmental challenges. Research on regulatory concerns is critical for ensuring the application of the concept of sustainable development in the building industry. China's regulation, on the other hand, suffers from a lack of supply and an ambiguous value orientation. The former is a symptom of the current regulatory structure, whereas the latter is the root of the problem. To overcome the value-oriented dilemma, some studies plan to conduct research using the logic of the norm. This has the disadvantage of having a limited field of vision. The interaction between man and nature should be considered while examining value orientation. When anthropocentrism, ecocentrism, and anthropocentrism in ecology are compared to the environmental legislation in my nation, it is clear that anthropocentrism in ecology is the value orientation that should be followed at the moment. Three challenges that require attention are presented based on this value orientation, as well as the uniqueness of the construction industry and risk society theory.
\end{abstract}

Keywords: Environmental pollution; Regulatory system; Anthropocentrism in ecology; Risk society

Publication date: November 2021; Online publication: November 30, 2021

\section{Introduction}

Sustainable development is a worldwide theme. Meeting the needs of sustainable development has gradually become a basic indicator of the construction industry. If environmental regulations, including the construction industry, are not handled properly, sustainable development will be the ultimate proposition for mankind. Sustainable development is to maintain a relatively balanced system of interaction between humans and the environment. The problem of environmental pollution has grown wildly in the originally balanced system, threatening the balance of the system. Human society has already entered a risk society. The gradually spreading environmental crisis has brought many problems to human society, such as the contradiction between human survival and development, and the contradiction between people.

The regulatory system provides the most fundamental and effective means, and the solution to environmental pollution should be reflected in the regulatory level. Regarding the legal regulation of environmental pollution, the theoretical circle began to discuss the value guidance of environmental pollution regulation, that is, dialectical analysis around anthropocentrism, ecocentrism and anthropocentrism in ecology. The Eighth Amendment to Chinese Criminal Law has changed the constitutional elements of the environmental pollution crime. This shows the value shift of environmental regulation and also confirms the root of the environmental pollution problem in the construction industry. At present, environmental pollution is a universal and worldwide problem. Although this article was formulated by the Criminal Law Amendment, the implementation mode and value orientation behind it are of great significance to the environmental pollution control and supervision of the construction industry. 


\section{The environmental pollution regulatory system needs to be improved urgently}

China's current environmental pollution regulatory system is in contradiction with the problem of environmental pollution. The problem of environmental pollution is characterized by a wide range and a complex situation. However, China's regulatory system has the problems of insufficient refinement and unclear value orientation. This will lead to insufficient supply of relevant rules, which will lead to two problems. On one hand, it cannot effectively control the environmental pollution problem; on the other hand, it may over-regulate environmental pollution issues, thereby hindering the development of the construction industry and even infringing on human rights. Whether it is unregulated or over-regulated, it deviates from the theme of the era of sustainable development.

\subsection{Regulatory rules are not detailed enough to cause regulatory failure}

Construction production will produce a large amount of construction waste and other environmental pollution problems, and the imperfect regulations of the relevant regulations have led to re-harm to the environment. my country is opposed to the problem of construction pollution, but it lacks penalties or penalties are not strong enough to form a deterrent. The recent changes in the environmental pollution regulatory system in my country show that the value concept of the regulatory system is accelerating the transformation, but this also confirms the problem of insufficient rule refinement.

For the environmental regulations of the construction industry, there is a serious problem of insufficient refinement. The protection of the environment in the Construction Law of the People's Republic of China is mainly a regulation of a "statement" nature. Regarding the specific regulatory method, it did not specify. my country's specific measures for environmental regulation of the construction industry are mainly manifested in departmental regulations, such as urban construction waste management regulations. In the specific regulations, the specific disposal methods are not sufficient. At the same time, the penalties stipulated by it are also very minor, and the opposite effect has occurred in practice.

Although the changes in some environmental regulations in the regulatory system herald the change of values, they also confirm the existence of the above-mentioned problems. The Supreme People's Court and the Supreme People's Procuratorate issued two interpretations to verify the tendency of legal rule construction. According to Table 1, it can be seen that the specific operating situations of the criminal law itself are showing an increasing trend, and the types of crimes of environmental pollution have transitioned from consequential offense to the parallel state of consequential offense and potential damage offense.

Table 1. Comparison of two judicial interpretations

\begin{tabular}{lcc}
\hline \multicolumn{1}{c}{ Styles } & $\begin{array}{c}\text { 2013 judicial } \\
\text { interpretation }\end{array}$ & $\begin{array}{c}\text { 2016 judicial } \\
\text { interpretation }\end{array}$ \\
\hline Number of specific cases of environmental pollution & 14 & 18 \\
\hline Number of specific cases of potential damage offense & 5 & 8 \\
\hline Number of specific cases of consequential offense & 8 & 9 \\
\hline Number of miscellaneous provisions & 1 & 1 \\
\hline
\end{tabular}

After the eighth amendment of the Chinese Criminal Law, it stipulates that "violating national regulations" and "seriously polluting the environment" are the elements for the crime of environmental pollution. Some people believe that this is a shift from anthropocentrism to ecological anthropocentrism, from consequential offense to potential damage offense, and weakens administrative subordination ${ }^{[1]}$. However, the adjustment method is still "based on administrative rules", and the tendency of administrative subordination has not changed ${ }^{[2]}$. Taking a step back, the current environmental laws, administrative 
regulations, and departmental regulations on environmental pollution regulations themselves also have inherent contradictions ${ }^{[3]}$. Therefore, the refinement of the types of legal regulations on environmental pollution is a problem that needs to be solved urgently.

\subsection{Value guidance needs to be clarified}

Compared with the improvement of the regulatory system, value guidance is a more fundamental issue. At present, there are three types of value guidance that need to be analyzed: anthropocentrism, ecocentrism, and anthropocentrism in ecology. The choice of these three-value guidance will correspond to different legal interests. From the perspective of anthropocentrism, administrative subordination is more reasonable; from the perspective of ecocentrism, the independence of criminal law is more reasonable; from the perspective of anthropocentrism in ecology, restricted administrative subordination is more reasonable. The relationship between value guidance and legal benefit is that value guidance determines legal benefit. However, there is currently a viewpoint in theoretical circles that value guidance is determined by the logic of criminal law. Of course, its essence is only used for reasoning and has not been expanded. For example, some people believe that if the legal benefit of environmental pollution protection is the environment itself, then the value guidance should be ecocentrism. There is an upside-down situation here, and the reason is that it cannot be investigated from the perspective of the evolution of a deeper level of human society.

From the above, it can be seen that there are obvious problems in the regulation of environmental pollution in my country, and there are obvious problems that need to be clarified and value guidance. The clarification of value guidance is the core issue and the starting point for further research.

\section{Anthropocentrism in ecology should be used as a value guide}

Whether it is anthropocentrism, ecocentrism, or so-called modern anthropocentrism, there are logical flaws and should not be used as a value guide for the current environmental pollution laws and regulations. The anthropocentrism in ecology has eliminated the conquering nature and the pursuit of destruction that have always existed in anthropocentrism that are not in line with the true pursuit of human beings.

\subsection{Anthropocentrism does not conform to the rule-building tendency}

From the perspective of the relationship between man and nature, some scholars divide the development stages of human society into agricultural society, industrial society, and ecological society, and point out that human beings are now living in an ecological society. At this time, human beings are facing severe challenges. Ecological issues. Anthropocentrism is caused by a one-sided view of the relationship between human beings and other things, and it treats self and others with the subject-object dichotomy. In the early days of human society, this approach would lead to the conquest of nature as the main theme of the time. Everything is human-centered, which has created a series of environmental problems. With the development of the times, the ills of anthropocentrism have gradually accumulated. Finally, it has become an urgent problem to be solved in the period of risk society. The environmental regulation system of the construction industry is difficult to form and operate scientifically. Similarly, anthropocentrism cannot provide more explanations for the legal benefits of environmental pollution crime protection, which will lead to a significant reduction in the meaning of "seriously polluting the environment". This not only does not conform to the spirit of its subsequent judicial interpretations, but also loses the possibility of more interpretations.

\subsection{Ecocentrism is the result of overcorrection}

In the research on the legal regulation of environmental pollution, while criticizing anthropocentrism, it also fell into the misunderstanding of ecocentrism, which is the result of overcorrection. Ecocentrism can 
prove that the environment can be protected by the regulatory system, but it is more accurate to express that only the environment can be protected by the regulatory system. The disadvantage is that it excludes the legal interests of human life and property, so it loses its meaning.

\subsection{Anthropocentrism in ecology is the return of value guidance}

The anthropocentrism in ecology means that only by protecting the environment in the natural living space of human beings can the life, body and other interests of human beings be protected ${ }^{[4]}$. This is the result of thinking deeply about the relationship between humans and the environment. Humans do not necessarily pollute the environment and destroy the ecology. Environmental pollution and ecological destruction are only the side effects of human beings in the practice of self-awareness and innovation. Humans allow the accumulation of side effects, but they do not actively pursue the production of side effects. The foothold and starting point of this value guidance is human beings. The environment should be protected because it has irreplaceable value to humans. Some people think that this is actually no different from anthropocentrism. This view is the result of confusing modern anthropocentrism and anthropocentrism. From a formal point of view, modern anthropocentrism can be expressed as anthropocentrism. This erroneous view is the result of confusing connotation and form. The anthropocentrism in ecology separates the subject-object dichotomy to view the relationship between humans and the environment. This is a substantial change, which makes the legitimate interests of mankind and the environment should be fully protected by the regulatory system.

\section{Issues that should be paid attention to in the construction of legal rules for environmental pollution} After clarifying the value guidance, the specific operation of transitioning it to legal rules should also pay attention to several issues. The construction of rules to regulate environmental pollution should combine the characteristics of legal regulations, risk society theory and the particularity of environmental pollution.

\subsection{Rules construction should strengthen cooperation with architectural designers}

At present, the research on regulatory issues in our country is decentralized, non-cooperative, and nonscientific. The specific refinement of environmental pollution regulations involves a large amount of chemical knowledge, ecological knowledge, environmental knowledge, etc. At present, there are few cooperative researches between scholars and architectural designers, and there are certain problems with its scientific nature. Some scholars pointed out the problems of dispersion and non-cooperation in related studies. The article also raises another problem, that is, the problem of disconnection from practice. Therefore, it is necessary to strengthen legal empirical research and sociological research, and integrate theory with practice. In combination, it is recommended to focus on using social research and statistics to analyze cases ${ }^{[5]}$. Therefore, the research of my country's regulatory system should establish interaction with architectural designers and strengthen cooperation research with specific architectural producers.

\subsection{Maintain a steady spiral of interpretation and legislation}

It is difficult to complement the regulatory rules of the construction industry in a short time, and it takes a long time to study such a large-scale regulatory system. Moreover, related regulatory issues are also in a state of continuous development, but the issues must be resolved. The law should be maintained, and stability should be maintained. Changing laws cannot form a stable and orderly society. The meaning is that large-scale legislative activities should not be carried out in the short term, but should be mitigated and sampled through interpretation, and the legal rule system should be gradually improved after amendments. For example, the criminal law stipulates that the two constituent elements of the crime of environmental pollution "violating national regulations" and "seriously polluting the environment" make the conditions 
for constructing crimes have more room for interpretation. "Violation of national regulations" can be interpreted as a violation of the criminal law, environmental law, administrative regulations, etc. This means that interpretation can be started from different laws, and there is more flexibility, but attention should be paid to issues of thoroughness, coordination, and protection of human rights. The element of "seriously polluting the environment" inherently contains the substantial result-type element of "serious consequences of major property damage and personal injury." Therefore, the legal benefit of the protection of environmental pollution crime can be human life and property, or the environment itself. This interpretation space and interpretation method are also compatible with the anthropocentrism in the ecology demonstrated in the second part. Of course, interpretation is not the end of legal regulation, but the end is the formation of a methodology for dealing with environmental pollution. Under the guidance of this value, the legal regulation of environmental pollution will gradually form a scientific system, adapt to the requirements of the times, and have a strong buffering effect on the future development of human society.

\subsection{Preventing the social enlargement of environmental risks}

The social amplification theory of risk proposed by scholars at Clark University's Policy Research Institute refers to the fact that risks enter the public through social media, and the public will receive exaggerated risk perceptions. Similarly, if environmental risks are amplified by social media, the public will have an exaggerated perception of them ${ }^{[6]}$. This is something that researchers among the public should avoid. Excessive environmental risk perception will lead to too conservative research on legal regulations. The current era not only needs to deal with environmental risks, but also needs to deal with development issues. An overly conservative legal regulation system will hinder development. "Pick up sesame seeds and lose watermelon" is not an ideal result. Exaggerated perception is a problem that should be avoided in research.

\section{Summary}

The main problem with the current environmental pollution regulation system is the clarity of value orientation. Solving this problem is of great significance to the environmental regulation of the construction industry. By reflecting on the relationship between man and nature, we can know that anthropocentrism in ecology is a deformation of anthropocentrism. Through the amendment, the connotation of the relationship between the subject and object of man and nature is eliminated, and the true connotation of man's dependence on nature is obtained. The revised anthropocentrism in ecology is the true value orientation of the turning process of the environmental pollution regulatory system, but we should also pay attention to the characteristics of the construction industry and the existing problems in current research. Considering the nature of environmental pollution as a by-product of industrialization, legal and regulatory research should deepen cooperation with architectural designers to ensure the scientific nature of research results.

\section{Disclosure statement}

The author declares no conflict of interest. This thesis is a conference paper of the 2021 2nd International Conference on New Energy Technology and Industrial Development (NETID 2021).

\section{References}

[1] Wang Y, 2014, Environmental Crime Legislation: Concept Change and Trend Forecast: Contemporary Law Review. 3:56-66.

[2] Xu Y, 2020, On the Distinguishing of Types of Chinese Environmental Legal Norms: Jilin University Journal Social Sciences Edition. 2: 66-74+220.

[3] Wu K, 2021, On the System Function and Normative Configuration of the General Provisions of the 
Environmental Code: Law and Social Development. 3: 167-188.

[4] Zhou G, 2016, Criminal Law: China Renmin University Press, Beijing.

[5] Zheng Z, Chen D, 2020, Knowledge Map of Environmental Law Research CSSCI (2009-2019), Literature Metering Analysis based on Citespace: Journal of Arid Land Resources and Environment. 6: $62-72$.

[6] Liu Q, Xu B, 2015, On the Systematic Reasons and Legal Countermeasures of the Social Amplification of Environment Risk. 10: 92-97. 